\title{
O Brasil no divã
}

DANIEL MARTINESCHEN ${ }^{I}$

Ó Senhor meu, dilata-me o peito;

facilita-me a tarefa;

E desata o nó de minha língua"

(Alcorão, 20:25-27)

ODA VIAGEM transforma. Desde o momento em que se toma a decisão da viagem, já existe uma transformação em curso - o viajante já não é mais o mesmo. Sairá de seu local conhecido, percorrerá um trajeto, e chegará a algum destino. Pode ser o destino almejado de início, pode ser outro - por ter mudado de ideia, por ter sido obrigado a desviar -, pode acabar retornando ao ponto de partida sem chegar ao destino inicial. De toda forma, estará transformado, diferente, com alguma nova ideia ou com concepções novas - mesmo o turista que apenas contabiliza mais um destino no passaporte também se transforma. E também o destino da viagem se transforma, de alguma maneira: um vilarejo passa a ter uma nova história, um novo conto de um estrangeiro que ali passou (pode ser até um estrangeiro do mesmo país), e pode até se transformar de aldeia rural num destino de peregrinação.

A viagem que tive o privilégio de fazer foi traduzir o West-östlicher Divan de Johann Wolfgang von Goethe, ${ }^{1}$ e também de fazer um doutorado sobre ele. ${ }^{2}$ Gostaria aqui, talvez pela primeira vez, de "abrir meu coração" e, na medida em que se me "desatar o nó da língua", fazer um relato honesto dessa viagem.

Pois se existe algo que uma viagem permite é a mudança de perspectiva. $\mathrm{O}$ que conhecemos em casa de repente ganha nova importância, maior ou menor. O que conhecemos durante a viagem - seja no trajeto, seja no destino -, por mais singelo que seja, modifica o que entendemos sobre nós mesmos, sobre nossa identidade e nosso pertencimento.

E o Divã Ocidento-Oriental é também o relato de uma viagem. É a viagem literária de Goethe pelo Oriente, pela Pérsia do poeta Hafez, ${ }^{3}$ pelo antigo mundo das Mil e uma noites, pela civilização antiga das histórias bíblicas - por mais anacrônico que isso soe hoje. E, dessa forma, nos conta uma história que diz tanto do estrangeiro quanto do próprio viajante, da sua visão de mundo e do quanto cedeu ou não à transformação.

O Divã foi escrito de 1814 a 1827, com uma primeira edição em 1819 e a segunda em 1827. O ano de 1814 para Goethe teve uma curiosa constelação de coincidências: a insatisfação com a monótona vida de homem de estado, na corte do Duque Carl August, que estava impelindo Goethe a uma nova fuga (como 
quando realizou sua Viagem à Itália); a solidão com a perda dos interlocutores da sua geração - Herder, Wieland e Schiller estavam mortos já havia anos; o medo pelo avanço das invasões napoleônicas (escreveu em seus Tag- und Jahreshefte de 1813: "Assim como no mundo político uma monstruosa ameaça se manifestava, na mesma medida me lancei com obstinação ao mais longínquo"4); o presente da tradução completa do Diwan de Hafez, da pena do austríaco Joseph von Hammer. E, com a tradução de Hafez na mala, Goethe iniciou sua viagem: para as termas próximas a Weimar, e em direção ao Oriente de Hafez.

Não foi qualquer viagem. Goethe leu avidamente todo o Diwan de Hafez antes de chegar às termas, e já na carruagem reagiu à leitura com seus próprios poemas, escrevendo em toda ocasião em que teve tempo livre. Uma torrente de mais de 100 poemas foi escrita no primeiro ano de trabalho sobre o Divã uma coletânea de amplitude inédita na produção de Goethe, e isso dentro de um ano. O primeiro que foi escrito, mas que não é o primeiro do Divã, trata do mito da criação do homem com uma ironia e um bom humor surpreendentes para o leitor que talvez esperasse uma abordagem mais sisuda sobre o tema:

Erschaffen und Beleben

Hans Adam war ein Erdenkloß,

Den Gott zum Menschen machte,

Doch bracht er aus der Mutter Schoß

Noch vieles Ungeschlachte.

Die Elohim zur Nas' hinein

Den besten Geist ihm bliesen,

Nun schien er schon was mehr zu sein,

Denn er fing an zu niesen.

Doch mit Gebein und Glied und Kopf

Blieb er ein halber Klumpen,

Bis endlich Noab für den Tropf

Das Wabre fand, den Humpen.

Der Klumpe fühlt sogleich den Schwung, Sobald er sich benetzet,

So wie der Teig durch Säuerung

Sich in Bewegung setzet.

So, Hafis, mag dein holder Sang,

Dein heiliges Exempel,

Uns fübren, bei der Gläser Klang, Zu uns'res Schöpfers Tempel. (DKV, p.18)
Criado e animado

Seu Adão, bolo de lama, Deus fez homem formoso;

Do ventre da mãe derrama

Seu aspecto horroroso.

Elohim no seu nariz

Sopraram um bom espírito.

Já se achou muito feliz

E logo deu um espirro.

Ossos, membros, cuca ao topo:

Nunca foi um bolo inteiro,

Até Noé achar o copo

Que pra gota é o verdadeiro.

O bolo sente o momento

Tão logo se umedece,

Como a massa, com fermento,

Que se mexe e logo cresce.

Hafez, que teu beato canto,

Teu santo exemplo,

Nos leve, taças em pranto,

Ao Seu divino templo. 
Não que Goethe não fosse já bastante cético, com uma crítica afiada e humor sutilmente ácido. Mas nesse poema nota-se uma transformação, resultante da viagem: de repente, depois de percorrer literariamente as terras do poeta persa, resolveu evocar o tema bíblico da criação do homem com grande jocosidade, remetendo-se por fim aos "beatos cantos" de Hafez - cuja poesia canta o vinho e a transgressão dos limites da religião como meio para a transcendência. $O$ panteísta Goethe de repente encharca de vinho a Bíblia, ajoelha-se num tapete muçulmano de oração e canta o mundo em embriaguez. A leitura de Hafez o impele de maneira quase incontrolável à poesia:

\section{Geständniss}

Was ist schwer zu verbergen? Das Fener! Denn bey Tage verräth's der Rauch, Bey Nacht die Flamme, das Ungehener.

Ferner ist schwer zu verbergen auch

Die Liebe, noch so stille gehegt, Sie doch gar leicht aus den Augen schlägt. Am schwersten zu bergen ist ein Gedicht, Man stellt es untern Scheffel nicht. Hat es der Dichter frisch gesungen, So ist er ganz davon durchdrungen, Hat er es zierlich nett geschrieben, Will er die ganze Welt soll's lieben. Er liest es jeden froh und laut, Ob es uns quält, ob es erbaut. (DKV, p.16)

\section{Confissão}

O que é ruim de esconder? O fogo! Se ao dia a fumaça o trai

À noite a chama o monstro, o ogro.

Mais difícil de esconder, ai!

O amor: guardado em cura calma, Pula ágil pra fora d'alma.

O pior mesmo é esconder um poema: Pois cobri-lo dá o maior problema. Se o poeta o recém-cantou, De poesia se encharcou; Se o poeta o escreveu com classe, Quer que todo o mundo o abrace. A todos lê, alegre e forte.

Azar de nós - ou será sorte?

A viagem não parou por aí. $\mathrm{O}$ interesse de Goethe pelo Oriente - uma designação difusa para uma região tão ampla e tão diversa do globo, como nos fala Edward Said em sua obra Orientalismo - não apenas se intensificou, mas renovou-se e trouxe lembranças de antigas leituras e outras viagens: a leitura do Corão; os estudos e traduções da literatura popular junto com o amigo-mentor Herder; a leitura crítica da Bíblia e o estudo do Cântico dos cânticos como poesia de amor. São todas lembranças que trouxeram novo viço ao poeta sexagenário, levando-o a iniciar um novo período produtivo, algo atípico para um autor nessa idade. O estudioso e biógrafo de Goethe Hartmut Reinhardt (2012, P.13) comenta:

Aos 64 anos, Goethe começou em 1814 com os trabalhos no “West-östlicher Divan", numa idade na qual as pessoas costumam se fiar mais ao que foi experimentado e preservado, e abriu mais uma vez seu horizonte literário para o estrangeiro. 
Assim deu-se a aparição de Hafez nel mezzo del camin, e Goethe se fez jovem de novo. Se uso aqui a palavra "aparição", é no sentido de "fenômeno", de um acontecimento fortuito - não estou falando de fantasmagoria. Falo aqui de um encontro rejuvenescedor:

Phänomen

Wenn zu der Regenwand

Phoebus sich gattet,

Gleich steht ein Bogenrand

Farbig beschattet.

Im Nebel gleichen Kreis

Seh ich gezogen,

Zwar ist der Bogen weiß,

Doch Himmelsbogen.

So sollst du, muntrer Greis,

Dich nicht betrüben.

Sind gleich die Haare weiß,

Doch wirst du lieben.

(DKV, p.19)
Aparição

Se ao muro de chuva

Febo se aninha,

Surge a sombra recurva,

E em cor rebrilha.

Vejo um mesmo arco

Traçado no véu;

Branco é mesmo o arco,

Mas arco-de-céu.

$\mathrm{Tu}$, velho querido,

Não deves chorar;

Teu cabelo é encanecido,

Mas tu vais amar.

E uma outra aparição se fez, e Goethe amou. Nos anos 1814 e 1815, cultivou uma relação muito próxima com Marianne von Willemer, esposa do banqueiro e amigo Jakob von Willemer. Uma amizade muito íntima, motivada tanto por admiração mútua quanto pelo interesse comum pela poesia e pelo talento poético de ambos - há quem diga que Marianne rivalizava com Goethe. Mantiveram longa e intensa correspondência, em grande parte cifrada, cuja chave (descoberta apenas décadas depois da morte de Goethe) foi o Diwan de Hafez - o livro central desse amor. E a relação de amor se deu pelo intermédio dos livros, de cartas e conversa, e por fim migrou para o Divã, eternizada no jogo de máscaras de Hatem e Zuleica do Livro de Zuleica - ainda que Goethe jamais tenha podido ou desejado admitir. ${ }^{5}$

E assim Goethe estendeu seu Divã em 12 livros de uma poesia que fala de amor, de guerra, da própria poesia, das religiões abraâmicas (islã, judaísmo e cristianismo) e da antiga religião persa do zoroastrismo, que canta a sabedoria popular e mística na forma de provérbios, ditos, parábolas e reflexões. Dessa forma Goethe "prestou contas poéticas" da sua viagem literária ao Oriente, e apresentou assim seu "poeta-irmão" Hafez e o Oriente que tanto admirava e prezava. O Oriente que Goethe traz no Divã é marcado por pureza e ingenuidade antigas, devoção religiosa superior, força poética ancestral, simplicidade de pensamento aliada a arrojo artístico; mas caracterizado também por violência, sangrenta 
vingança, dominação através da força, exotismo e erotismo que causam deleite, espanto e admiração ao leitor ocidental. Retornarei a essa visada adiante.

E assim, quando termina a parte de poesia do Divã (mas não a poesia do Divã), deparamos com uma longa seção em prosa, aberta por esta singela quadrinha:

Wer das Dichten will verstehen

Muß in's Land der Dichtung gehen;

Wer den Dichter will verstehen

Muß in Dichters Lande gehen.

(DKV, p.137)
Fosse entender a poesia, Pra sua terra viajaria; Fosse entender o poeta, Nas suas terras andaria.

No centro do livro, entre a parte de poesia e a parte de prosa, reforçando o convite à viagem (para a terra da poesia e do poeta), temos um fractal em tetrâmetros trocaicos que representa todo o Diva a ${ }^{6} \mathrm{O}$ primeiro dístico reproduz de maneira condensada os doze livros de poesia do Diva a, onde se encontra a "terra da poesia". O segundo dístico anuncia as "Notas", que descrevem o território por onde o poeta transita: seus autores, suas leituras, suas conviç̧ões. Se o leitor percorre o trajeto da viagem do Divã desde seu início, chega aqui como que numa passagem, num terreno elevado, e esse poema como que o lança a uma altura ainda maior, da qual pode divisar as "terras poéticas" que compreendem a viagem. Para um lado, a "terra da poesia", para outro, as "terras do poeta". E a beleza do fractal é essa: um pedaço pequeno da estrutura remonta à estrutura em escala maior, como a espiral de uma concha ou um floco de neve. Sem precisar recomeçar nem folhear o livro, o leitor é convidado a abrir o horizonte, pausar na caminhada e contemplar os meandros poéticos percorridos logo atrás, expandindo assim o fôlego e se preparando para uma nova etapa da viagem. A "quadratura do círculo" do poema - a regularidade do verso alemão acomodando a "fluidez" espiral do Oriente - como que aninha o Divã e se aninha em si mesma.

Se virmos os poemas do Divã como imagens, "clics" (como diria Leminski) criativos do viajante sobre o que experimentou durante sua jornada, as "Notas para uma melhor compreensão"7 poderiam ser lidas como um verdadeiro diário da viagem, no qual Goethe conta, com sua habitual e poderosa prosa, os caminhos de leitura que percorreu para compor o Divã. E a viagem de Goethe pelo Oriente de Hafez, diferentemente do que nos conta na Viagem à Itália, ${ }^{8}$ foi uma viagem feita exclusivamente pelos livros, pelas leituras, pelas traduções.

E é nessas "Notas" que chegamos a um pequeno capítulo na qual está condensada a reflexão teórica de Goethe sobre tradução, que é muito mais importante do que parece, sobretudo para entender o modo de apropriação praticado no Divã. O capítulo "Traduções" traz uma classificação das traduções em três "épocas", que representariam fases da aproximação/apropriação entre dois estrangeiros, sendo o receptor normalmente mais ativo que o recebido. ${ }^{9}$ Cito-as de maneira resumida: 
[...] O primeiro [tipo de tradução] nos familiariza com o estrangeiro no nosso próprio sentido, e neste caso uma tradução simples-prosaica é a melhor. [...] Uma segunda época se segue, na qual de fato nos esforçamos nos colocar na condição do estrangeiro, mas na verdade apenas nos apropriamos do sentido estrangeiro e o reapresentamos segundo nosso sentido caseiro. Tal época gostaria de chamar, no mais puro sentido da palavra, de parodística. [...] Como não se pode permanecer nem na perfeição nem na imperfeição por muito tempo, mas uma transformação sempre deve se seguir a outra, assim vivemos o terceiro período, que deve ser considerado o mais elevado e o último, ou seja, aquele no qual se deseja tornar a tradução idêntica ao original, de modo que um não deva existir em vez do outro, mas sim no lugar do outro. (DKV, p.280-1, grifos meus)

Pois é aqui que o relato de Goethe me parece fornecer a chave para uma releitura dessa viagem. "Releitura" porque o gesto intercultural de Goethe para alcançar o estrangeiro Hafez é tido como um gesto prenhe de desprendimento, boa vontade e compreensão. Muito já se especulou nos estudos do Divã que ele seja uma tradução do terceiro tipo, o amálgama cultural em que as fronteiras se borram. A beleza da poesia do Divã é incontestável; mas nessa poesia não transparece a poesia de Hafez nem se borram as fronteiras: é a poesia de Goethe que resplandece, em máxima potência. Tanto assim que a representação do Oriente e de Hafez teve por resultado a afirmação de Goethe como grande intermediador "ocidento-oriental" para a poesia de Hafez.

Não é que Goethe não tenha descrito o modo segundo o qual retrataria o poeta estrangeiro, ou seja, que utilizaria os moldes da própria poesia alemã, sem investir num projeto radicalizante. Contudo, parece que uma narrativa que se construiu sobre o Divã tem prevalecido sobre o que está dito na própria obra. Ora, Goethe escreve na "Introdução" às "Notas":

$\mathrm{O}$ autor dos presentes poemas prefere ser visto como um viajante que merece o elogio se conseguir assimilar com afinco o modo específico estrangeiro, se conseguir se apropriar dos usos da língua, se souber partilhar modos de pensar e aceitar costumes. Que seja perdoado caso isso só the seja possível até um determinado grau e caso permaneça claramente estrangeiro devido a um acento próprio e a uma inflexibilidade indomável de seus conterrâneos. (DKV, p.138-9, grifos meus)

Goethe pede desculpas prévias pelas suas próprias limitações e por não ser tão radical quanto talvez o leitor esperasse. ${ }^{10}$ Além disso, o poeta evoca a "inflexibilidade indomável" de seus conterrâneos, ou seja: seu público não entenderia um projeto de importação revolucionária de uma poesia tão radicalmente outra. Não se trata de mera "desculpa": um projeto muito mais radical e revolucionário, o de Friedrich Rückert, não teve o mesmo prestígio que o de Goethe, e até hoje o erudito de Schweinfurt permanece à sombra do poeta de Weimar. ${ }^{11}$

Há uma boa dose de cálculo nessa atitude de Goethe, algo que encontramos também em outro momento da história do Divã. Em 1817, Goethe havia 
enviado alguns poemas a uma revista para testar a reação do público e de seus críticos. O feedback que recebeu foi de confusão, por não ter ficado claro se ele apresentou traduções de poesia persa ou se escrevia poemas inspirados por essa temática. Goethe preferiu não resolver essa confusão, e anotaria posteriormente:

A prévia enviada ao [periódico] Damenkalender também mais confundiu o público do que o preparou. A ambiguidade, de serem [os poemas] traduções ou imitações inspiradas ou apropriadas, não teve bons resultados para o empreendimento; deixei, contudo, que tudo seguisse o seu curso, já acostumado a ver o público alemão tropeçar até que consiga receber e apreciar [algo novo]. (DKV, p.734)

Aqui aparece novamente a suposta "inflexibilidade" do público leitor alemão. Mas para o projeto de Goethe foi importante que não se esclarecesse essa ambiguidade, pois assim ele poderia manter o controle da narrativa sobre o Divã . Goethe desejava uma boa recepção ao seu livro: "Não quero que nada obstrua a primeira boa impressão do presente livrinho", como diz na "Introdução", e também expressou esse desejo ao seu editor Friedrich Cotta em uma carta: "Esse divã alemão desejo [ver] na forma de um livro de bolso em muitas mãos [...]". ${ }^{12}$

Talvez Goethe pensasse que um projeto radical ou revolucionário obstruísse a circulação ampla e a recepção amigável do público alemão. Contudo, por ironia do destino o Divã foi um fracasso retumbante, como comenta Michael Knaupp (1999, p.527):

Tão popular o Divã se dá por vezes na sua forma, apesar disso não é um livro popular, mas tem algo que o afasta da compreensão imediata. A coexistência de sabedoria de velhice e tolice de amor, a união de louvor aos príncipes e entusiasmo pelo Oriente, a mistura de jogo mundano e ânsia religiosa irritou os contemporâneos de Goethe, e não deve espantar que quase cem anos após a publicação do Divã ainda houvesse exemplares disponíveis para compra na editora.

A grande obra intercultural de Goethe, o livro gerado pela viagem poética transformadora, a tradução "superior" que deveria derrubar fronteiras e ilustrar o diálogo de culturas tão distantes, tornou-se o que o comentador Hendrik Birus chama de "um livro sob sete selos". Incompreensível mas belo e fluente; estrangeiro, mas não tanto; transformador mas conservador; criado com o destino de ser um livro do povo, mas transformado em iguaria para especialistas. Como lidar com essa "aparição" tão singular na obra de Goethe, e o que é que ela pode dizer a nós sobre o estrangeiro, sobre nós e sobre o estrangeiro em nós?

O papel da crítica é desconstruir, num sentido que Derrida expressou certa vez: “o gesto da desconstrução consiste em não naturalizar o que não é natural", 13 ou seja, colocar tudo em perspectiva e em contexto. Desconstrução não é destruição, desmantelamento, como os críticos dessa vertente dizem. Desconstruir é escancarar as estruturas e superestruturas, não aceitá-las como dadas, naturais, perenes. 

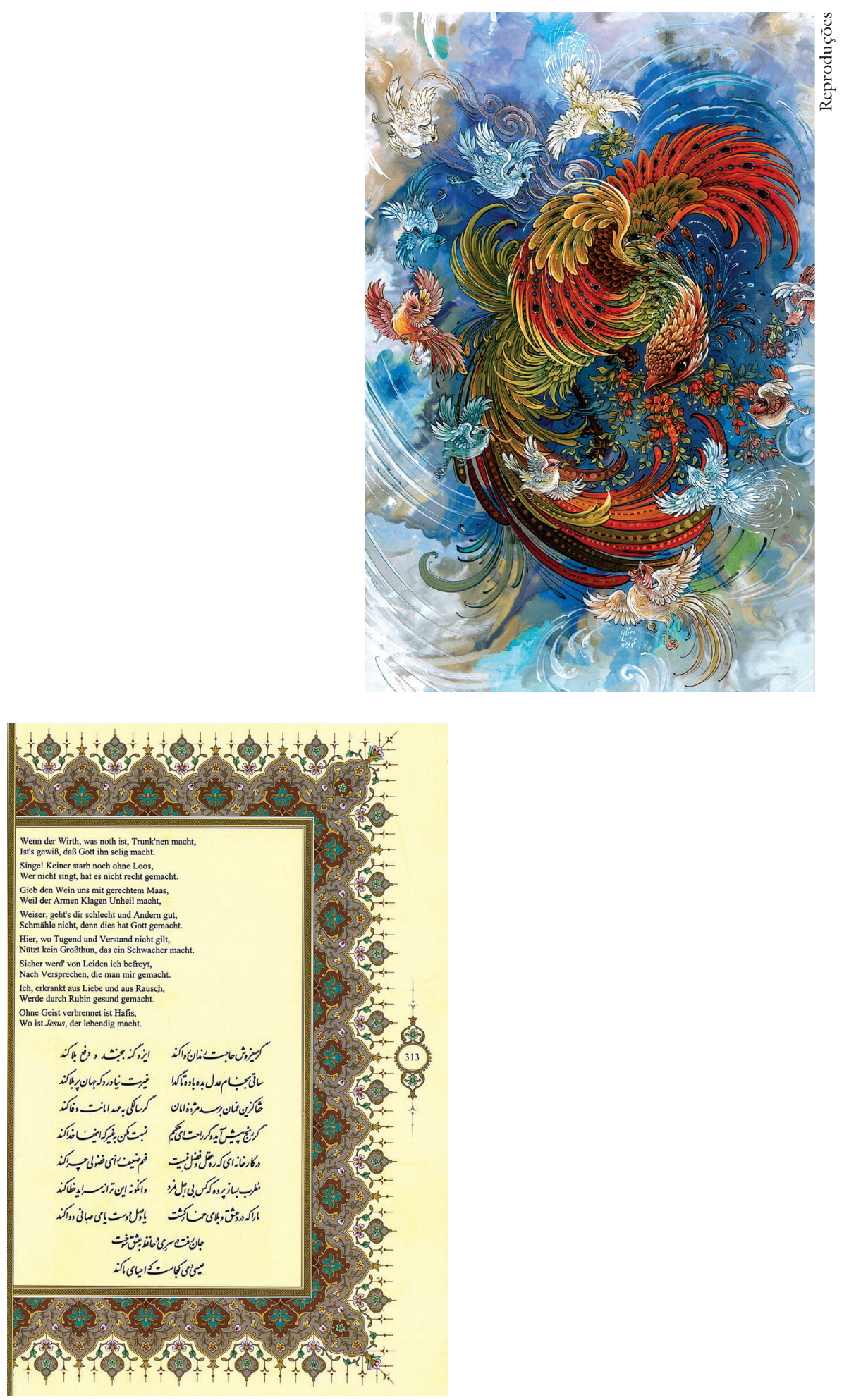

Ilustração para uma edição persa-alemã, impressa na cidade de Shiraz (Irã), do Divã de Hafiz. A tradução alemã do gazel (do árabe ghazal, teia ou trama) estampado ao lado provém do diplomata e orientalista austriaco Joseph von Hammer-Purgstall (1774-1854), que traduziu na integra esse ciclo lírico (diwân, em persa: "arquivo, coletânea de escritos") de Hafiz. 
E se há algo a desconstruir sobre o Divã - e, às vésperas de a tradução dele começar a circular, o momento é crucial - é a compreensão da imagem do autor e da leitura que ele faz do Oriente. Essa leitura encerra muitos interesses, para além do diálogo interliterário. Goethe reage à poesia de Hafez segundo seus moldes e interesses próprios, e apesar de as mais das vezes ser um homem à frente de seu tempo, também é um homem imerso no seu tempo. Em outras palavras: sua visão não se desvia das lentes orientalistas europeias do século XIX tanto quanto desejamos enxergar.

E a escrita poética de Goethe reflete essa visão, aproximando-se muito do modo "parodístico" das traduções, pois se insere nos moldes que ele já dominava com desenvoltura: os da literatura alemã. É uma poesia que não parece efetivamente contaminar a língua/literatura de chegada, mas que fala do estrangeiro em seus próprios termos. O poeta diz isso explicitamente na "Introdução":

Antes de qualquer coisa, nosso poeta se permite declarar que se comprometeu em primeiro lugar, na ética e na estética, com a compreensibilidade; por isso, empenhou-se em usar a linguagem mais simples e a métrica mais leve e compreensivel de seu dialeto, e a sugerir só muito vagamente aquilo no que o oriental encontra o seu deleite por meio de artificialidade e afetação. (DKV, p.138-9, grifos meus)

Primar pela "compreensibilidade" e pela "simplicidade" é um gesto domesticador, não de uma experiência radical do estrangeiro. Então, não deveriam causar espanto a beleza e a fluência da poesia do Divã, como nas palavras de Heine, que parecem conter um tempero de ironia quando diz que no Diva temos versos "tão leves, tão felizes, tão sussurrados, tão etéreos, que nos admiramos de que algo assim seja possível em língua alemã" (Heine, 2002, p.55-6).

O poeta Oskar Loerke (2012, p.366) escreveu que "Hafez emigrou para dentro de Goethe, e Goethe para dentro de Hafez". É uma afirmação bastante elogiosa e generalizante, cuja primeira parte é de fácil constatação - Hafez é um elemento constante na poesia do Divã. Já a segunda demanda uma reflexão mais profunda. Como afirmei no início, toda viagem transforma, inclusive o próprio destino da viagem se transforma. Mas como se apura isso? Como se pode afirmar que Hafez e sua obra tenham sido alterados pela poesia do Divã ? ${ }^{14}$

A "via de duas mãos" do gesto tradutório se dá de maneira muito concreta pela veiculação do traduzido pelo tradutor e pela vinculação do primeiro ao segundo. $\mathrm{O}$ tradutor não promove modificações apenas na língua/cultura de chegada, mas o autor traduzido também se transforma, sendo associado a esse tradutor, que passa a ser visto como mediador nessa relação intercultural. ${ }^{15} \mathrm{E}$ com o Divã Ocidento-Oriental ocorre algo semelhante. Goethe se esforçou para se firmar como mediador entre Hafez e seus leitores ocidentais, mais do que outros autores que propiciaram acesso mais amplo à obra do poeta persa - como Joseph von Hammer ou Friedrich Rückert -, e até hoje essa associação se perpetua. Tanto em textos dedicados à obra de $\mathrm{Hafez}^{16}$ quanto textos de caráter mais 
informativo e genérico (como a Wikipedia ou a Encyclopaedia Iranica), diz-se que Hafez foi o poeta cantado por Goethe no Divã. A dificuldade de acesso à poesia de Hafez, uma aura exótica em torno da sua pessoa e da poesia persa em geral, e a suposta necessidade de estudos necessários para se acessar sua poesia interditam de certa forma o acesso ao poeta persa, e assim o caminho "indireto" oferecido por Goethe se afigura como mais prático ou até mais confortável.

Em uma de suas Máximas, Goethe reflete sobre a relação entre observador e objeto: "Na observação da natureza, no maior como no menor, me faço incessantemente a pergunta: é o objeto ou é você que aqui se exprime?" (Goethe, 1981, p.314). ${ }^{17}$ Ao observar o Oriente, tanto em escala micro quanto macro, o que é que se exprime no Divã : é o Oriente ou é o próprio observador?

O Oriente que Goethe nos apresentou não diferia muito do que circulava na Europa do século XIX. Edward Said já nos contou do Orientalismo europeu, que criou uma ideia de "Oriente" para veicular o domínio da Europa sobre essa vasta e variada região do planeta. Said critica o "Orientalismo de biblioteca" de Goethe (e de outros autores) pelo fato de prescindir do conhecimento direto e de se fiar apenas no que se encontrava nos livros - relatos de viagens, estudos, traduções. ${ }^{18} \mathrm{~A}$ imagem do oriental que se construiu é cheia de pureza e ingenuidade, de devoção religiosa e ao mesmo tempo ânsia de vingança, de beleza poética na linguagem e nas ações cotidianas e ao mesmo tempo sensualidade e exotismo.

$\mathrm{Na}$ afirmação mais conhecida sobre literatura mundial (que, na verdade, conhecemos de segunda mão através do livro de Eckermann), Goethe diz o seguinte: "Literatura nacional não quer dizer muita coisa agora, a época da literatura mundial está chegando, e todos devem trabalhar para acelerar a sua chegada" (Eckermann, 2002, p.237-8, tradução minha). Dentro desse conceito, Goethe parecia enxergar que uma obra tinha que circular, e para isso precisava ser traduzida. ${ }^{19} \mathrm{~A}$ tradução de que a literatura mundial se serve é aquela que faz de fato com que as obras circulem, sejam lidas e compreendidas e, o que é muito importante, que sejam vendidas. Ou seja, é a tradução que aproxima a obra do leitor, reescrevendo elementos da literatura estrangeira com os recursos da língua/literatura de chegada. De fato na tradução permanecem elementos estrangeiros, mas me parece existir um limite do que é aceito enquanto estrangeiro. O Divã parece ter tentado transgredir esse limite ao emular (ou fingir) uma presença marcante do estrangeiro dentro da poesia alemã.

Há aqueles que consideram o Divã Ocidento-Oriental como a obra par excellence da literatura mundial, com uma sua visada de tolerância e integração (poderíamos dizer antropofagia?) para com o poeta oriental para trazê-lo para dentro da literatura alemã e ocidental. De fato, se considerarmos que legibilidade e fluidez são características de uma obra que circula no mundo, o Divã cumpre esse requisito, como atesta o comentário de Heinrich Heine e como podemos constatar na leitura da poesia. Contudo, isso parece não ter sido su- 
ficiente para que o Divã se tornasse de fato um veículo para a poesia persa no Ocidente, pois permanece até hoje numa posição relativamente obscura dentro da obra do poeta. O exotismo espanta, apesar da fluidez; a largueza da prosa desanima, apesar de conter elucidação e muita honestidade para com o leitor, principalmente para entendermos as fontes e o modo de trabalho do poeta; o diálogo almejado com Hafez parece se perder num eco da própria voz de Goethe, dentro da ambiguidade entre tradução e produção própria que parece mais confundir do que atrair à leitura.

Não seria o gesto tradutório um gesto fundamental e indispensável para a concretização da literatura mundial? De fato, são muitos os entendimentos sobre o que seja literatura mundial. Muito já se especulou sobre o que exatamente Goethe quis dizer na sua célebre frase. Não almejo entrar nessa discussão, nem discutir seus pormenores e implicações para a compreensão do mercado livreiro ou da literatura comparada. Mas algo tenho como certo: não existe literatura mundial sem a tradução. Qualquer obra que almeje circular entre um grupo grande de leitores não pode permanecer intraduzida, imersa dentro da sua literatura e de sua língua.

Talvez Goethe tenha tentado, com o Divã, dar um passo com uma perna grande demais; ou, dito de outra forma, tentado uma experiência que talvez o público leitor de então não estivesse pronto para receber - estaria o público leitor de hoje mais "pronto" para essa experiência? O Divã - mesmo com um inevitável olhar "orientalista" da época e do autor, mesmo com uma realização prática muito mais domesticadora do que estrangeirizante - parece ter proposto uma forma de tradução para além dos métodos e das comparações, para além da monetização do livro e da literatura, para além da postura tradutória simplificadora e domesticadora que faz com que um livro circule no mercado literário. Uma forma de tradução profunda, que mexe com convicções pessoais - ainda que dentro de limites - e instaura um diálogo literário que, talvez, seja mais radical que o intercâmbio linguístico e textual possa dar a perceber na superfície.

Goethe não apresenta Hafez no Divã. Goethe é Hafez. Assumiu o lugar de Hafez com uma poesia ocidental que remete a uma poesia oriental. Não é Hafez que fala na poesia do Divã , como talvez falasse numa tradução em sentido mais estrito, mas é uma ideia de Hafez que está presente nessa poesia. Como um "estrangeiro transplantado", Hafez é idealizado, e o grande idealizador aqui é Goethe. Talvez neste aspecto Goethe tenha conseguido atingir o terceiro tipo de tradução, no qual "um não deve existir $e m$ vez do outro, mas sim no lugar do outro". Tomando o lugar de Hafez, Goethe parece ter criado um espaço para que Hafez circulasse para fora das culturas em que é conhecido (persa, turca, árabe), e mesmo com todas as reservas que devemos ter com relação a apropriação cultural, o legado do Divã aponta para o que Goethe vislumbrava em uma de suas "Máximas e reflexões": "A tolerância deve na verdade ser apenas uma disposição transitória: ela deve conduzir ao reconhecimento. Tolerar é ofender". ${ }^{20}$ 
Pois então, que possamos passar da tolerância à aceitação, ao reconhecimento. E, ainda mais nesse momento histórico, não é possível pensar na própria ideia de estrangeiro, da aceitação da estranheza e do reconhecimento do "outro" sem voltar os olhos para o que ocorre em nosso país. Pois um povo que não se apercebe de si mesmo não consegue valorizar a riqueza sob seus pés e sobre sua cabeça. Não reconhece o nativo como irmão, como parente, como antepassado. Não sabe senão olhar para si e para o resto do mundo com as lentes do colonizador, permeado pela ideia irrealizável entranhada em sua autoimagem, em sua autoestima. Não se dirige ao reconhecimento [Anerkennung], o objetivo final da tolerância - essa atitude revestida de verniz tão brilhante que mascara uma relação de desigualdade e de condescendência.

$\mathrm{O}$ estrangeiro dentro de nós é mais nativo que o nosso nativo. Temos "europeus transplantados" dentro de nós, uma ideia fundada em melancolia e desprezo pelos nativos e pobres brasileiros que não permitem que reconheçamos nossa condição de latino-americanos. Até quando iremos tolerar esse estrangeiro transplantado? Quando reconheceremos quem somos de fato? Nativos de uma nação, deitada no berço esplêndido da discriminação e da separação, cuja força real é a união na diferença, é aceitação de que o que é forte é vário, mesclado, puro na miscigenação de tantas forças individuais.

Concluo esta reflexão com uma provocação sobre a formação da identidade nacional brasileira e o quanto de verdade que pode haver no que diz Amleto Ferreira (ou dizemos nós?) no grande tratado sociológico-literário em que João Ubaldo Ribeiro grita Viva o povo brasileiro:

Mas, vejamos bem, que será aquilo que chamamos de povo? Seguramente não é essa massa rude, de iletrados, enfermiços, encarquilhados, impaludados, mestiços e negros. A isso não se pode chamar um povo, não era isso o que mostraríamos a um estrangeiro como exemplo do nosso povo. $O$ nosso povo é um de nós, ou seja, um como os próprios europeus. As classes trabalhadoras não podem passar disso, não serão jamais povo. Povo é raça, é cultura, é civilização, é afirmação, é nacionalidade, não é o rebotalho dessa mesma nacionalidade. Mesmo depuradas, como prevejo, as classes trabalhadoras não serão jamais o povo brasileiro, eis que esse povo será representado pela classe dirigente, única que verdadeiramente faz jus a foros de civilização e cultura nos moldes superiores europeus - pois quem somos nós senão europeus transplantados? Não podemos perder isto de vista, deixando-nos cair no erro abismal de explorar nossas riquezas e nossa virtual grandeza para entregá-las a esse tal povo, que, em primeiro lugar, não saberia como gerir tão portentosa herança, $\log o$ a aviltaria, como sabe, aliás, quem quer já tenha tentado dar conforto e regalias a escravos e servos, pois não atinam com o que fazer desse conforto e dessas regalias. (Ribeiro, 2011, cap.8, grifos meus) 


\section{Notas}

1 Essa tradução, a ser publicada em 2019 pela Estação Liberdade, terá como título Divã Ocidento-Oriental. Minhas razões para essa tradução do título podem ser encontradas na minha tese de doutorado (Martineschen, 2016). Enquanto a edição não vem a lume, faço referência à edição da Deutscher Klassiker Verlag do Divã (Goethe, 2010) com a sigla DKV seguida da indicação de página.

2 Cf. Martineschen $(2014 ; 2016)$. Se me contraponho aqui a algumas ideias que formulei nesses trabalhos, é porque o tempo permitiu uma contemplação mais imparcial e distanciada. Além disso, a crise de identidade nacional que vivemos desnudou, pelo menos para mim, muitos rancores e ideais que formam a nossa ideia de nação brasileira - o que me levou a repensar meu panegírico ao Divã.

3 Khwāja Šamsu d-Dīn Muhammad Hāfez-e Šīrāzī foi um poeta, teólogo e místico persa, nascido (provavelmente) por volta de 1320 e falecido em 1389 em Xiraz, no sudoeste do atual Irã. Escreveu uma poesia de amor, contestação política, de enfrentamento do rigor religioso do Islã, numa mistura do cotidiano com a mística e com o amor mundano e transcendental. Seu Diwan é sua obra mais conhecida, com centenas de gazéis ("divã" é a palavra do persa para "coletânea", e representa a reunião de todos os poemas de um autor). Ler mais em <http://www.iranicaonline.org/articles/hafez>.

4 Citado em DKV (p.726).

5 Pelo menos três poemas do Divã são de autoria confirmada de Marianne von Willemer (como atesta o germanista Herman Grimm (1869)): Bendita teu amor me faz (Hochbeglückt in deiner Liebe), O que é o movimento? (Was bedeutet die Bewegung?) e $A$ h, das tuas úmidas alas (Ach, um deine feuchten Schwingen), os dois últimos conhecidos respectivamente como Canção do vento Leste e Canção do vento Oeste. Curiosamente, esses são os poemas do Divã que mais foram musicados como Kunstlieder-justamente os que não são de sua autoria.

$6 \mathrm{O}$ fractal é uma estrutura matemática recursiva e autossimilar que descreve uma estrutura que se repete tanto num nível microscópico quanto macroscópico. A espiral da concha do caracol, o floco de neve, a folha da samambaia, cardumes de peixes e bandos de aves (que parecem versões grandes dos pequenos animais), um brócoli com suas flores, a espiral do girassol.

7 O Oriente do Divã é o Oriente Médio, compreendendo sobretudo a região do atual Irã, Iraque e a Península Arábica, bem como a região dominada pelo Império Otomano.

8 Mirella Guidotti (2012) escreve sobre a construção da estética (visual) goetheana a partir da experiência da viagem que empreendeu à Itália em 1786-1788, como um esforço de fugir de teorias, livros, preconcepções para formar sua compreensão através da aisthesis, da apreensão pelos sentidos. É interessante notar aqui que, como aponta Guidotti, a Viagem à Itália foi escrita entre 1816-1817, na mesma época em que Goethe escrevia o Divã e estava passando justamente por um período de tristeza, desinteresse e introspecção, devido em parte à dolorosa morte de sua esposa Christiane. Guidotti menciona que na mesma época Goethe se envolve com sua autobiografia e com o segundo romance de Wilhelm Meister; mas passa-lhe despercebida a viagem literária de Goethe ao Oriente, imerso em leituras variadas, em vários idiomas, uma viagem feita exclusivamente nos livros. Talvez essa viagem pelos livros tenha exercido efeito sobre o mencionado "ímpeto estetizante" na retrospectiva de sua vida produti- 
va, gerando-se assim uma imagem do Goethe adulto que talvez o mostre mais maduro e autoconsciente do que realmente foi.

9 Remeto o leitor ao capítulo correspondente do Divã , seja na minha tradução ou na tradução de Rosvitha Friesen Blume em Heidermann (2010, p.28-35). Para uma discussão mais longa sobre a tipologia de tradução de Goethe, remeto o leitor à tese de Antonella Nicoletti (2012) e à minha tese (Martineschen, 2016), incluindo muitos dos trabalhos que cito lá, como os de João Azenha Jr. (2003; 2006).

10 O que é falso, pois "radical” não é um adjetivo que se aplique a esse autor. A irrupção, a revolução, a transformação brusca não lhe causam apreço - como não lhe causou apreço a Revolução de 1789.

11 O jornalista Christoph Meyer (2016) é bastante enfático quando escreve: "Esqueçam Goethe, leiam Rückert".

12 Citado em Knaupp (1999, p.564-5).

13 Trecho do documentário Derrida (Derrida, 2002).

14 A resposta ao Divã a partir da poesia de língua persa demorou pouco mais de um século, com o Payam-e-Mashriq (Mensagem do Oriente) publicado em 1923 pelo poeta nacional do Paquistão Muhammad Iqbal.

15 É claro que não esquecemos aqui as barbaridades anonimizadoras e apropriadoras do trabalho de tradutores, como os inúmeros casos já denunciados por Denise Bottmann em seu blog "Não gosto de plágio". Penso aqui num caso ideal (que, porém, ocorre na realidade) de o tradutor ter sua atividade de mediação reconhecida e prestigiada dentro da interação interliteraturas.

16 Como, dentre tantos outros exemplos, o prefácio de J. C. Bürgel à coletânea Gedichte aus dem Diwan de Hafez (1972).

17 Tiro a citação dessa máxima do texto de Mirella Guidotti (2012).

18 Said atenuaria sua crítica ao orientalismo "de biblioteca" de Goethe, entendendo que o poeta alemão tinha sim sua boa intenção em se voltar ao Oriente e à divulgação da poesia de povos "marginais" (não-centro-europeus). A orquestra internacional West-östlicher Divan, fundada por Said em conjunto com o maestro Daniel Barenboim, é expressão dessa atenuação, e se dedica a promover, através da música erudita, o diálogo entre povos, com músicos palestinos e israelenses em suas fileiras.

19 Sobre a fúria de tudo traduzir, vide o catálogo da exposição Weltliteratur. Die Lust am Übersetzen im Jahrhundert Goethes [Literatura mundial. O prazer de traduzir no século de Goethe] do Museu Schiller em Marbach (Tgahrt, 1982).

20 Toleranz sollte eigentlich nur eine vorübergehende Gesinnung sein: Sie muss zur Anerkennung fübren. Dulden heißt beleidigen.

\section{Referências}

AZENHA JUNIOR, J. Tradução é movimento: uma leitura do Romantismo alemão. , n.14, jan./jun. 2003, p.31-56.

Goethe e a tradução: a construção da identidade na dinâmica da diferença. , n.9, p.44-59, 2006. 
ECKERMANN, J. P. . Mit 48 Abbildungen. Herausgegeben von Otto Schönberger. Stuttgart: Reclam, 2002 [1828].

FELSNER, K.; HELBIG, H.; MANZ, T. . Berlim: Akademie Verlag, 2012.

GOETHE, J. W. von. Goethes Werke in zwölf Bänden. Berlin; Weimar: Aufbau-Verlag, 1981.

West-östlicher Divan. Studienausgabe. Herausgegeben von Michael Knaupp.

Stuttgart: Reclam, 1999.

West-östlicher Divan. Org. Hendrik Birus. Berlim: Deutscher Klassiker Verlag,

2010. 2v. (DKV)

West-östlicher Divan. Herausgegeben und erläutert von Hans-J. Weitz. Mit Essays zum 'Divan' von Hugo von Hofmannsthal, Oskar Loerke und Karl Krolow. Berlim: Insel Verlag, 2012.

GRIMM, H. Goethe und Suleika. Zur Erinnerung an Marianne von Willemer. In: Preußische Jahrbücher. Org. H. v. Treitsche e W. Wehrenpfennig. Berlim: Georg Reimer, 1869. v.24.

GUIDOTTI, M. A construção do olhar: a Viagem à Itália, de Goethe. Pandaemonium, São Paulo, v.15, n.19, p.122-36, jul. 2012.

HAFEZ, M. S.. Gedichte aus dem Diwan. Sel. e org. Johann Christoph Bürgel. Stuttgart: Philipp Reclam, 1972.

HEIDERMANN, W. Clássicos da teoria da tradução. 2.ed. rev. ampl. Florianópolis: UFSC/Núcleo de Pesquisas em Literatura e Tradução, 2010. v.l: Alemão-Português.

HEINE, H. Die romantische Schule. Kritische Ausgabe. Herausgegeben von Helga Weidmann.Stuttgart: Reclam, 2002 [1836].

KNAUPP, M. „Zu dieser Ausgabe“. In: GOETHE, J. W. West-östlicher Divan. Stuttgart: Reclam, 1999. p.525-35.

LOERKE, O. Der Goethe des „West-östlichen Divans“. In: GOETHE, J. W. v. West-östlicher Divan. Herausgegeben und erläutert von Hans-J. Weitz. Mit Essays zum 'Divan' von Hugo von Hofmannsthal, Oskar Loerke und Karl Krolow. Berlim: Insel Verlag, 2012. [1925], p.364-78.

MARTINESCHEN, D. Traduzindo o Divan de Goethe: um encontro com a Weltliteratur. Revista Brasileira, Rio de Janeiro, fase VIII, n.79, ano III, p.15-26, abril-maio-junho 2014a.

O lugar da tradução no West-östlicher Divan de Goethe. Curitiba, 2016. 315p. Tese (Doutorado em Letras) - Setor de Ciências Humanas, Universidade Federal do Paraná. Curitiba, 2016.

MEYER, C. Vergesst Goethe, lest Rückert. Süddeutsche Zeitung, Munique, 31 de janeiro de 2016. Disponível em: <http://www.sueddeutsche.de/kultur/-todestag-von-friedrich-rueckert-vergesst-goethe-lest-rueckert-1.2842772 >. Acesso em: 2 fev. 2019.

NICOLETTI, A. Übersetzung als Auslegung in Goethes West-östlichem Divan im Kontext frühromantischer Übersetzungstheorie und Hermeneutik. Tübingen, Basileia: A. Francke, 2002. 
REINHARDT, H. Dem Fremden freundlich zugetan. Interkulturelle Bezüge in Goethes literarischem Werk. Nordhausen: Bautz, 2012.

RIBEIRO, J. U. Viva o povo brasileiro. [recurso eletrônico]. Rio de Janeiro: Objetiva, 2011.

TGAHRT, R. Weltliteratur: Die Lust am Übersetzen im Jahrhundert Goethes. Eine Ausstellung des Deutschen Literaturarchivs im Schiller-Nationalmuseum. Marbach am Neckar: Deutsche Schillergesellschaft, 1982.

WAGENKNECHT, C. Deutsche Metrik: eine historische Einführung. C. H. Beck, 2007.

RESUMO - O presente ensaio fala sobre o Divã Ocidento-Oriental de Goethe e o contempla pelo prisma da relação com uma literatura/cultura estrangeira. São discutidos aspectos relativos a gênese, autoria, recepção e tradução dessa/nessa obra, num mesmo movimento em que teço uma crítica à forma com que Goethe se apropria de uma imagem do poeta persa Hafez e reflito sobre a realização da tipologia tradutória proposta no Divã. Por fim, o leitor é convidado a refletir a respeito da identidade nacional brasileira a partir do que chamo aqui de "estrangeiro transplantado".

PALAVRAS-CHAVE: Goethe, Divã Ocidento-Oriental, Tradução, Identidade, Brasil.

ABSTRACT - This essay discusses Goethe's West-eastern Divan and examines it through the prism of its relationship with a foreign literature/culture. I discuss aspects of the genesis, authorship, reception and translation of/in this book, and in the same movement I criticize Goethe's appropriation of an image of the Persian poet Hafiz and reflect upon the actual translation typology proposed in Divan. Lastly, the reader is invited to think about the Brazilian national identity from the viewpoint of what I call here a "transplanted foreigner".

KErWORDs: Goethe, West-eastern Divan, Translation, Identity, Brazil.

Daniel Martineschen é bacharel e doutor em Literatura e Tradução pela Universidade Federal do Paraná. Traduziu e comentou o Divã Ocidento-Oriental, de Goethe (Estação Liberdade, 2019). Possui graduação e mestrado em Ciência da Computação. Atualmente dedica-se à tradução profissional, técnica, juramentada e literária.

@ - martineschen@gmail.com / https://orcid.org/0000-0002-2909-1861

${ }^{\mathrm{I}}$ Universidade Federal do Paraná, Curitiba, PR. Brasil.

Recebido em 27.2.2019 e aceito em 9.5.2019. 